\title{
The History of Public Relations in Greece from 1950 to 1980:
}

\section{Professionalization of the "art"}

\section{Introduction}

The oxymoron when researching the history of public relations (PR) in Greece is that even though Greek PR literature reports ancient Greece as the birthplace of PR (or at least claims that Greeks were among the first to practice a form of PR, among other highly respected civilizations of ancient times such as the Sumerians, Babylonians, and Romans) there is no systematic historiographical attempt (L'Etang, 2008) to approach the topic. The references to ancient Greece and Greek philosophers (Plato, Thoukididis and Aristotle to name a few) with regard to PR mostly focus on the values of logos, ethos and pathos, the concept of persuasion, the principles of argument setting and the balance of power, but they do not refer to any similarities with contemporary integrated PR campaigns (Papatriantafyllou, 2008; Panigyrakis \& Ventoura, 2001; Papalexandris, 2001; Theodoratos, 1999; Zompanakis, 1968; Zompanakis, 1965). Greek PR literature, responding to the needs of the industry, has mainly focused on PR functions and practice rather than researching PR's evolution in the country. In a few texts, it is briefly acknowledged in an introductory chapter or the appendices (Panigyrakis \& Ventoura, 2001; Papalexandris, 2001; Yannas, 2004).

This paper explores a field which has not been rigorously investigated and therefore will offer a fresh insight which may lead to better understanding of the business practice of PR in Greece. 


\section{2. (Hi)stories and Public Relations}

As it is necessary to explore the past in order to understand the present and move to the future it should be noted that the significant developments have occurred over the last five years, such as the establishment of the International History of Public Relations Conference (IHPRC) since 2009 and the constitution of the European Public Relations History Network (EPRHN) in 2012, which have placed PR history back in the research agenda. The literature covering the field PR history varies in approach, focus and output depending on the historian's assumptions, values and methodological approach (L’Etang, 2008). Indicatively Raaz \& Wehmeier (2011) reviewed 36 PR history books and articles drawn from Britain (1), Germany (11) and the US (24). They reported that: a) the progressivist approach dominates the US studies, b) the non-progressivist with a robust historiographical approach is followed by the British approach, while c) PR history research in Germany has been approached with mixture of methodological approaches which either borrowed elements from US outputs and applied to the German case or showed no interest in what has been done in Britain and US and focused clearly on the governmental activities which influenced and shaped German PR.

Since 2008, almost 150 papers or articles have been published on the history of public relations (Watson, 2013). They have explored different aspects, following a mixture of research methods and presenting cases from numerous different countries. These have been classified in the IHPRC, rather bluntly as Watson (2013) commented, in six categories, namely Historiography, History \& Events, Professional \& Practice, National Histories, Theories of PR and Proto-PR, with the papers being categorized in a three part typology (i.e. analytic, descriptive, critical). 
These categories and typologies allow public relations historians to develop comparative resources and map national histories, in particular, by their methodologies. In this case, the exploration of PR's evolution in Greece follows the UK, US, Italy, Spanish model at theoretical and/or practical level.

\section{Methodology}

Following Watson's (2013) classification the current study falls under the category of a national history and as the theme is related to describing and reconstructing the past it follows a descriptive typology (Tosh 2009, Watson 2013). Based on outputs of previous studies conducted in the Mediterranean region (Bini, Fasce \& Falconi, 2008; Rodriguez Salcedo, 2008), the research objectives are identification of 1) early developments and main actors; 2) the characteristics of national practices; 3) the international influences on the shaping of the area, the professional bodies and 4) the field of practice (Bini et al, 2008). Because there is a lack of published literature on the history of public relations in Greece, this study used a three-phase research approach to explore the various aspects. The historiographical approach followed is derived from Bentele’s Fact and Event-Oriented Type, where facts were described in a historical order with a focus on leading personalities (Watson, 2013).

In phase one, archival research was undertaken. Archival materials are one of the four types of unobtrusive measures where the researcher observes the evidence without having any interaction (Webb et al 1966 cited in Bryman, 2008). The initial archive investigated was that of the International Public Relations Association (IPRA) from 1955 to 2002 (Watson, 2011). Its catalogue was scanned for references to Greece and the bureaucratic archive (minutes and 
reports) of the organisation was then reviewed in detail. The IPRA archive, which is held at Bournemouth University, was chosen as it indicated the mid- $20^{\text {th }}$ century relationship between pioneering Greek public relations figures and the emerging international public relations scene. The archive provided more than 40 references about Greece.

In the second phase, three in-depth interviews were conducted in in Greece in order to achieve the research objectives but most importantly to answer wider questions regarding the development of Greek PR. The opinions of three highly-regarded practitioners offered valuable insight. While conducting the interviews, the researcher acknowledged the risks of the three interviewees being important personalities of the field with large experience (L'Etang, 2008) and proceeded with a narrative enquiry (Daymon \& Holloway, 2011) to explore the meaning that the stories told by the interviewees regarding the evolving practice of PR in Greece. Close collaboration with the Greek Institute of Communication (IoC) and personal research enabled access to the interviewees. The interviews were conducted with Marcel Yoel, Andrew Rizopoulos and Rita Malikouti in summer 2013. The interview guide was adapted from L'Etang (2008), which focused on: a) autobiographical information, b) view of the changes of the professionalization and c) opinion on PR scope and function (p. 258). Besides translating the interview guide into Greek, modifications were made in order to meet the research objectives of the current research. The questions were open, thus giving the opportunity to the interviewees to express their experience and opinions openly and without time constraints (L’Etang, 2008).

Finally, in phase three, desk research was undertaken. According to the interviewees and IoC, a rich archive of case studies and Greek PR literature has been donated over the years to the latter. 
Membership of IoC granted access to books, recorded interviews and enhanced support. The research aimed to explore all articles, books and case studies which were published before 1980 . A number of books were found, unfortunately without any case studies or articles. The Greek PR literature investigated covered the period from 1961 (earliest book) to 1980. Approximately 30 books (courtesy of IoC) including a recorded interview with a pioneer practitioner of Greek PR, Manos Pavlidis, were examined.

\section{Findings}

\subsection{Early developments of Greek PR and IPRA}

There are a number of historical aspects influencing the political, social and economic landscape which have to be acknowledged and set the context for the development of PR. Greece came out of WWII and Nazi occupation (1945) and a civil war (1949) just before the 1950s. The period from 1950 to 1974 was considered to be the legacy of the civil war counting several election processes and a seven-year military junta (Clogg, 2002, p. 142). The period after 1974 marked the start of a new era and the reinstatement of democracy. After WWII and the Yalta conference in 1945 which decided that Greece "belongs to the West", foreign countries and companies were encouraged to invest in the country. These investments, besides the financial benefits, came with knowledge transfer and the development of new fields of expertise. Public relations, as a scientific area which could lead, support and enhance business decisions, was one of these new fields.

The concept of PR was initially introduced when D. Clarke (Communication Director of Marshall Plan) discussed an offer of funds to the owner of Hotel Grande Bretagne in Athens 
(Petrakopoulos) “to do PR”. The Hotel Grande Bretagne was the grandest hotel in the Greek capital and temporary home to many investors and government representatives. The question arising at the time was "What is PR?” (IoC, 2007a). At that starting point, one of the individuals who attended the meeting turned out to (later) be seen the "father" of Greek PR, Manos Pavlidis. Pavlidis was working closely with Petrakopoulos (and Hotel Grande Bretagne) and therefore had the opportunity to meet all major personalities visiting Greece after WWII, including Clarke (IoC, 2007a). The term "Public Relations” was used officially for the first time in 1951 when the Greek National Tourism Organization (EOT) appointed the US-owned adverting agency Foote, Cone and Belding (Zompanakis, 1974; Magkliveras, 1970; Koutoupis, 1992; IoC, 2007a; IoC, 2007b,) on a six month contract to develop a tourism campaign (Magkliveras, 1970). This aimed to “promote/advertise” Greece as a tourist destination to France, UK, Germany and US (Koutoupis, 1992; IoC, 2007a). The campaign was to have been led by British PR adviser Eric Williams in collaboration with Manos Pavlidis (Koutoupis, 1992; IoC, 2007a). At that time Pavlidis was co-founder of one of the most reputed advertising agencies, ADEL, and partner with one of the leading personalities of Greek advertising Chrysostomos Papadopoulos (Koutoupis, 1992; IoC, 2007a). Even though the funds allocated for this project from the Marshall Plan were reallocated for other (mainly military) purposes (IoC, 2007a), this was the first time that the practice of PR was consciously and officially discussed (A. Rizopoulos, personal communication, June 13, 2013).

The first time that the term "Public Relations" is found in writing was in the mid-50s when private consultancy Embasco assisted in the development of the organizational structure of the Public Power Corporation SA (DEH) (IoC, 2007a). When the term was translated a debate arose 
as whether the meaning of the translation ("Dimosies Sxeseis" in Greek) reflected accurately on the values of the concept (Papamichalakis, 1961; IoC, 2007a; A. Rizopoulos, personal communication, June 13, 2013; Magkliveras, 1968; Zobarakis 1970; Tsiligiannis (1973). The translation does not reflect on the actual value and the meaning of concept of relationship nor does it highlight the importance of the humanitarian aspect.

It could be argued that when the term was initially used in writing there were no PR agencies operating or any PR experts to make a case. Rizopoulos (personal communication, June 13, 2013) recalls that in the mid-50s there were mainly three PR agencies (referred to as "offices") operating with Gerasimos Apostolatos (later a deputy minister for Social Services) founding "Orizon” ("OPIZ $\Omega N ")$ in 1954 being the first. In the absence of PR agencies and PR experts, advertising agencies were to become the first business partners of international agencies and consultancies which wanted to operate in Greece. Collaboration between an international consultancy, operating in the field of marketing, advertising or PR wanting to expand in Greece or in cases having to collaborate due to legislation issues (R. Malikouti, personal communication, June 10, 2013), led to partnerships with advertising agencies as the obvious and often only choice. Hence Greek public relations practices largely evolved from advertising agencies. Rizopoulos (personal communication, June 13, 2013) recalls that "when large advertising agencies saw the value of PR they began asking from people who knew about PR (starting with Pavlidis) to offer consultancy on the PR elements for their clients”. As the new profession started to form, the next step for the practitioners involved was learn more about the field and to start finding clients of their own. The challenge to attract clients was immense (M. Yoel, personal communication, June 12, 2013). Not only were the clients not aware of what PR is, they also 
kept insisting that the PR practitioner to do advertising for them (IoC, 2007b). As a result, when Pavlidis founded his own agency named "Desmos" (1957) he continued working closely with advertising agencies and especially ADEL, where he delivered PR elements within advertising campaign (IoC, 2007a). Similarly, Yoel, having worked in PR for Apostolatos and “Orizon” in 1957, was the first to establish a subsidiary advertising agency while being the owner of a PR agency (IoC, 2007b).

The PR practitioners started turning to the global market in order to develop their network, learn more about PR and seek clients. Rizopoulos (personal communication, June 13, 2013) says that Pavlidis was the first, followed by Yoel, to expand internationally. Both pioneers got actively involved with the International Public Relations Association (IPRA) in the early 1960s (Watson, 2011) in order to expand their network and opened the way for the rest to follow (Apostolatos is an exception, since he and Pavlidis were actually the first two to join IPRA; after 1960 his involvement wasn’t consistent).

In 1960, as more PR practitioners started establishing their own agencies, a decision was reached to form the Hellenic Public Relations Association (HPRA) (Zompanakis, 1968). The professional body, which was a genuine act of interest and good intentions from all parties involved (M. Yoel, personal communication, June 12, 2013), aimed to achieve: a) a professional association, b) educational development, and c) awareness within the country and internationally (A. Rizopoulos, personal communication, June 13, 2013). HPRA gave substance to the PR profession (A. Rizopoulos, personal communication, June 13, 2013) and was “recognized” by IPRA Council in Hague (Hague Council Minutes, 1960, p. 9) in the same year (Watson, 2011). 
In the following year, Manos Pavlidis (who was the first Greek practitioner to be nominated to IPRA membership in 1959) and G. Apostolatos were the first Greeks elected to IPRA Council, which set the association's policy. Pavlidis and, in 1961, Marcel Yoel undertook a range of highlevel responsibilities while being members of IPRA such as Chairman of Professional Practices Committee (Pavlidis, 1962 and 1963), member of Executive Committee (Pavlidis, 1963), Secretary of IPRA (Pavlidis, 1964 -1971), Treasurer of IPRA (Yoel, 1964 - 1972), Vice president of IPRA (Pavlidis, 1971) and President of IPRA (Pavlidis, 1973 - 1980). One of the last archived reports mentioning the active involvement of Greek members in IPRA came in 1980 when the 20th anniversary of the Hellenic Public Relations Association (HPRA) was celebrated in Athens. The anniversary was opened by Pavlidis (a past President of both HPRA and IPRA) in a speech titled, "Critical analysis of the PR function in a society of communication - the new professional requirements”. During the Athens stage of the European Confederation of Public Relations (CERP) annual conference and a joint HPRA event, Lucien Matrat (the French founder president of CERP) was presented with the 'Gold Efthynos of Public Relations’ by HPRA to celebrate the 15th anniversary of the approval of the Code of Athens in 1965. IPRA's ethics statement, written by Matrat, was adopted by IPRA in Athens. There was, however, negligible Greek input other than Pavlidis’ support for it. 


\subsection{International influences}

There is an evident international influence through the whole period. The financial aid, the investments made by international companies and the lead that US PR literature gave had a major impact on the development of PR in Greece. Pavlidis noted the importance of multinational companies operating in Greece, such as Mobil, Shell and Siemens which had inhouse PR departments (IoC, 2007a). Yannas (2004) also noted that Shell, Mobil, BP, Philips and American Express established continuing PR programmes in the 1950s and 1960s. The knowledge transferred from these organizations was a valuable addition to the international literature and the international partners and bodies (i.e. IPRA) they relied on. PR literature in English was dominant with US figures such as Ivy Lee, Edward Bernays, Bertrand Canfield and Denny Griswold, being referenced in many Greek PR books of the time (Zobanakis, 1965, 1968; Magkliveras, 1968, 1970, 1971; Magnisalis, 1972). Additionally Pavlidis (IoC, 2007a) and Rizopoulos (personal communication, June 13, 2013) mention during their interviews that the vast majority of books they used and, later donated to the Institute of Communication, were written by US scholars. Exploring the effect of US literature, it is noticeable when discussing their views on PR both stated that it should be seen as a managerial function which when placed on an organizational chart should be depicted as a role with consulting responsibilities reporting to directly to the CEO (similar to the status of a legal advisor) and not under or at the same grade with any other manager (i.e. marketing, finance, HR). For Rizopoulos (personal communication, June 13, 2013) the aforementioned was the first category. He proposed three additional categories. The second was “propaganda”, which is what ministries and public organizations are doing when communicating, the third is "relationship with the press”, involving press releases and communicating with journalists, while the fourth 
category (which is rather recent) is "marketing and PR", where the PR consultant reports to the marketing manager. Moreover understanding that the tactical elements of a PR campaign were more tangible when pitching to clients, there was an obvious effort from the Greek literature to discuss, in a similar manner with English literature, how PR tools support the PR functions and tactics (Magkliveras, 1968; Bokovou, 1974).

This US influence became more balanced after 1960 (and perhaps around 1965 when considering the unavoidable lag) when Greek practitioners started associating through IPRA with Lucian Matrat and the French school of thought. Pavlidis admired Matrat and considered him "a philosopher of European PR” (IoC, 2007a). Pavlidis highlighted the effect and overall role of PR in modern society and the responsibility of PR practitioners to deliver their mission ethically and therefore was one of Matrat's supporters with regard to the development of the Code of Athens (IoC, 2007a). The peculiarity observed is that Greek PR appears (in theory) to be a combination of both American and European school of thought, with the American side having a greater influence. Indicatively, Zobanakis (1965) states:

As supported by sociologists, the power of public opinion will be stronger in the future affecting the activities of all social and economic groups. The social and economic groups which will attempt to influence the public opinion will find it much more difficult and will need to rely on a more systematic and organized approach.

Similarly, Magkliveras (1970) defines PR as:

The systematic effort of a company or an individual, based on a plan to develop through social contribution a relationship with the general public - regardless if this public is 
interested or not in the service provided - in order to create positive reputation and prestige.

Pavlidis and Magkliveras (cited in Magkliveras 1970) suggested a more socially-oriented definition to the HPRA (without this definition being accepted):

Public relations is the executive function of the administration of a public organization or a private organization or any social structure which researches public attitudes towards them aiming with appropriate behaviour and systematic communication to develop a positive attitude and a sustainable cooperation with all social groups which may directly or indirectly - affect the operation of the specific organization.

Additionally, Magkliveras quotes Pavlidis in his second edition of the same book:

PR aims to establish socially a firm or an organization, constantly improving the reputation, developing a positive public opinion, while at the same time adjusting to the public's opinion which they communicate back to the public [...] while advertising is a project with a start and an end. PR does not have an end, never stops, has continuity and does not aim to sell a specific product in a specific time. PR aims to establish the firm socially (Imerisia 3-1-1965).

The science of PR was new and therefore most practitioners (with Pavlidis undoubtedly leading the discussion) were trying to understand the unknown. The European school of thought was closer and more relevant to the majority's educational background and the county's culture; however the US offered a new profitable and more enterprising model. 


\subsection{Professional bodies}

IPRA and the (British) Institute for Public Relations were the most influential bodies of the time for Greek PR practice and even though they did not attempt at any point to influence the developments of the practice in the country, Greek PR practitioners subconsciously developed the need to establish a similar professional PR body. Being a member of an international body was a good opportunity to develop as a professional, prestigious for the individuals and an opportunity to build a network (R. Malikouti, personal communication, June 10, 2013; M. Yoel, personal communication, June 12, 2013; A. Rizopoulos, personal communication, June 13, 2013). All interviewees agreed that it was the personal interest of the practitioner that led to the decision to become members and was not a systematic approach to share best practices between professional bodies or develop training opportunities. As Yoel (personal communication, June 12, 2013) discussed, IPRA was not interested into getting involved in how PR was practiced in Greece and did not influence policy. Through IPRA a practitioner could get clients through the international network. Pavlidis and Yoel managed to develop a strong network of contacts and prestigious client lists. The network and the ability to attract national but most importantly international accounts were significantly enhanced once he (Yoel) became an IPRA member. Enhancing the international network for the Greek PR practitioners was another reason that HPRA was developed. Rizopoulos (personal communication, June 13, 2013) and Malikouti (personal communication, June 10, 2013) acknowledge that being the head of HPRA made the practitioner also the main point of reference internationally. All three interviewees agreed that the rivalry that resulted was one of the main reasons that HPRA faded as an institution such that, as far as PR practitioners were concerned, it ceased to exist. Today the national professional body of PR is a sub-sector of the Hellenic Association of Advertising and Communication 
Agencies (EDEE) which has operated in this form since 2000. EDEE is an expansion and reformation of the Hellenic Association of Advertising Agencies which was established in 1968. Public affairs, sponsorship and event marketing are now under the umbrella of PR members' activities. One of the most noteworthy ventures was the establishment of the Institute of Communication in 2002 in an attempt to bridge the gap between academia and industry.

\subsection{Field of practice}

While exploring the PR books written in Greek, it appears that all authors (and pioneers of the field) were highly profiled and well-educated individuals. Even though education might not be the first skill needed in PR, it is definitely the essential second cultivating and framing the way of thinking (A. Rizopoulos, personal communication, June 13, 2013). It is evident that the authors of the first PR books were influenced by their educational background when approaching PR. Indicatively: Katsioulas (1964) attempts to enrich scholarly PR literature with psychology (MA \& PhD Psychology and Education), Tsiligiannis (1973) discussed the effects of applied anthropology on PR (BA Law), Mpokovou (1974) connects the possible role that PR may have in the economic development (PhD in Economics and Political Science), while Magnisalis (1972) makes a clear connection between PR and human relations (PhD Political Science). Moreover, education may occasionally define the mode of practice. Reflecting on the 1960s and how PR was practiced Yoel (personal communication, June 12, 2013) commented: “There were certain elements that one has to have and certain knowledge when working for a client / employer. Not all of us had that and therefore had to do other stuff like organizing trade shows etc which we called PR.” 
The educational background of the pioneers might have been diverse; however the profile of the individuals practicing PR followed a pattern. According to Rizopoulos (personal communication, June 13, 2013) they could be clustered as journalists or advertisers. As the clients of the PR practitioners (mainly) expected and asked for media entries, both clusters perceived themselves as suitable. On one hand, journalists, those who were former journalists, freelance journalists or anyone who had some kind of journalistic experience, based their expertise on personal media network. On the other hand, the advertisers saw PR as part of the wider advertising practice. Rizopoulos (personal communication, June 13, 2013) elaborates and explains that acknowledging the time and available mediums, a press release had occasionally many similarities with a print media advertisement, especially when few people knew what PR was. Rizopoulos (2013) argues that there were two routes followed when advertisers practiced PR: They either did advertising and not PR, which meant that they treated the press release as a print media advertisement and got expenses approval by the finance department of the agency and then mailed it to the journalists; Or they offered PR as a service provided with advertising. Within the advertising deal that the advertiser had with the medium s/he occasionally mailed a press release. The journalist, appreciating the existing advertising deal and aiming to sustain it, published the press release. Yoel (personal communication, June 12, 2013) recalls: "I had a number of times difficulties trying to explain to the journalists when sending a press release that I was not doing it to get free advertising, but for publicity”.

With regard to the field of practice, Magkliveras $(1965,1970)$ expressed his views on the necessity of introducing or carrying on using PR almost in every field of practice. He considered that public sector organizations should start approaching citizens in a more personal manner and 
that PR should be used by military forces and from state services in order to develop relationships with international organizations like NATO and UNESCO. Following Papamichalakis (1961), Magkliveras $(1968,1970)$ mentioned that PR has been used by the Greek Orthodox Church, when organizing the celebration of the 1900th anniversary of the apostle’s Paul arrival in Greece. Zobanakis (1970), following Papamichalakis (1961), discussed how PR was used by a number of Greek banks on a strategic and tactical level making it clear that the bank sector was one of the leaders in adopting PR practice. Among the corporate and brand leaders in practicing PR were Pavlidis' accounts, with examples such as IZOLA (largest Greek company for kitchen/home appliances of his time) and Peiraiki-Patraiki (largest Greek textile producer of the time) and Yoel's accounts such as the multi-store "Minion” group, which was one of the first clients to clearly ask for consultancy on PR and not advertising. Yoel (personal communication, June 12, 2013) also worked on accounts from various industries while supporting US consultancy Hill \& Knowlton on the $11^{\text {th }}$ World Scout Jamboree in 1963, which was sponsored by Gillette, Marathon Oil and Marathon Typewriters. Yoel was appointed to do the PR for all three their accounts. In most, if not all cases, and especially those developed by Pavlidis and Yoel the influence of US practices were evident where extensive communication strategies aiming to influence positive word of mouth were undertaken systematically (Watson, 2008).

\section{Conclusions}

This paper places the history of Greek PR on the map of European public relations historiography. As it is probably one of the few (if not only) to tell the story and acknowledging 
that the historiographical approach links with Bentele’s Fact and Event-Oriented Type, one has to accept that history has in most cases many different angles (Raaz \& Wehmeier, 2011).

According to the findings, a highly active, well-educated and self-selecting elite of 20 to 25 people led the evolution of PR in Greece, with two prominent leaders taking a significant role internationally in IPRA from 1950 to1980. The members of this group authored almost all Greek books on PR published during this period. These books presented the use and practical angles of PR, with a personalised practitioner perspective. Being influenced mainly by literature written in English (i.e. US and British literature) and occasionally French, various views regarding the nature, social responsibility and business practice of PR were presented, often with case studies drawn from the banking sector. The authors’ personal views, which were not always scholarly justified, revealed different dynamics within the group, demonstrated overall understanding about PR and an eagerness to educate about the new scientific area. Even though a Greek school of PR thought cannot be clearly identified, the practice of PR was not solely based on the dominant international PR theories.

As Bini et al (2008) observe, the development and importance of PR in the UK was state-driven (L’Etang, 2004 cited in Bini et al, 2008), in the US it was driven by corporations (Marchand, 1998 cited in Bini et al, 2008), while in Italy the families leading Fiat and Piaggio had valuable input in developing a national school of thought (Bini et al, 2008). The Greek case was more complicated. Its initial focus was on business PR; however this was limited to the extent that both organizations (i.e. EOT and DEH) through which PR was initially mentioned were public companies. It is debatable of whether or not the state introduced PR intentionally. It was, 
corporations and private initiatives which mainly developed PR in Greece. These initiatives were not, however, comparable with the initiatives that corporations undertook in the US and Italy. Moreover, unforeseen events had occasionally major influences. For example, as the economic infrastructure of the country could not support effectively large companies of the time, this resulted to either bankruptcy (e.g. IZOLA, Peiraiki-Patraiki) or close-down after accidents (e.g. fire in MINION store). These events were major setbacks for PR, as these companies were convinced of the value of PR but had to shut their doors; as they could not repay debts or had to make PR personnel and agencies redundant.

The evolution of PR was driven mainly by US and British corporations (investing in Greece after WWII and the 1946-49 Civil War) and the personal interest of enlightened practitioners who formed the PR professional bodies. These organizations could be seen as the institutions which externalized the representation of PR; however, it was the personality of the pioneers constituting the professional bodies which had greatest impact on external audiences and the reputation of the practice than any other factor.

The research output of this study, despite limitations, offers evidence that the history of Greek PR is rich and culturally different to US and other European experience. The PR profession in Greece celebrated the French school of thought and Matrat, while at the same time pragmatically following US and UK practice. This study provides an additional source for understanding and developing the practice and scholarship of the field in the future. 


\section{Limitations}

Over this period the country suffered from heavy political propaganda which has not been explored. Although there are references to the Greek Church being the first to practice PR (Papamichalakis, 1961; Magkliveras, 1968), there is little scholarly evidence put forward. In any case, this paper has focused on the development of business-related PR and found no linkages with religious promotion and propaganda in its formation. Finally, there were some difficulties accessing data. Unfortunately, Pavlidis’ work was mainly published in articles which are not included in publicly-accessible archives, such as the IoC in Athens. There was a similar problem with the Papamichalakis archive, whose career is mentioned in Koutoupis (1992) and was referred to by Rizopoulos (personal communication, June 13, 2013).

\section{Future Research}

There are strong indications that PR was initially used for business purposes by Greek industries from the 1950s onwards. Future research can explore, following the methodological approach of structuralist periodization (Bentele, 2009 as cited in Watson 2013), the historic development of governmental and political PR. How was government and political PR applied when shaping or polarizing public opinion before, during and after historic events (e.g. Balkan Wars, WWI, WWII, Civil War, Military Junta, etc.) with an impact on the political, social and economic life of the country? Additionally, the question of whether or not certain historical events (i.e. the Civil War) could be explored as forms of dissent and protest PR could also be researched. Finally, motivated by Koutoupis’ (1992), observation that the pioneers who led PR were not 
succeeded by continuing generations of far-sighted leaders may be a theme to explore in the history of Greek PR after 1980. 


\section{References}

Bini, E., Fasce, F., \& Muzi Falconi, T. (2011). The origins and early developments of public relations in Italy, 1945-1960. Journal of Communication Management, 15 (3), 210-222.

Bryman, A., (2008). Social research methods. (3rd ed.). Oxford: Oxford University Press.

Clogg, R. (2002). A Concise History of Greece. (2nd ed.). Cambridge: Cambridge University Press.

Daymon, C., \& Holloway, I. (2011). Qualitative research methods in public relations and marketing communications ( $2^{\text {nd }}$ edn). London: Routledge.

Institute of Communication (IoC), (Producer). (2007a). Interview with Manos Pavlidis. Athens, Greece.

Institute of Communication (IoC), (Producer). (2007b). Interview with Marcel Yoel. Athens, Greece.

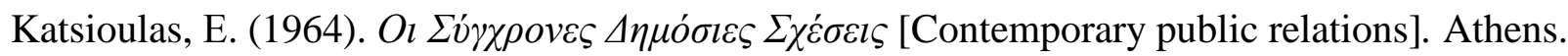

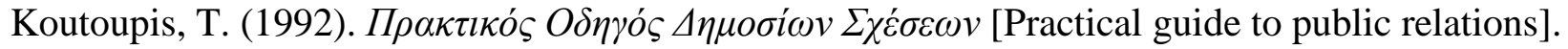

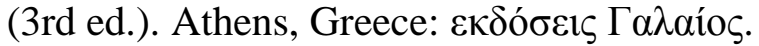

Hellenic Association of Advertising \& Communication Agencies. (2011), $\Delta \iota \alpha \varphi \eta \dot{\mu} \sigma \eta \eta \kappa \alpha \iota$ $\varepsilon \pi \imath \kappa o \imath v \omega v i ́ \alpha \sigma \varepsilon \alpha \rho \imath \mu$ ov́ [Advertising and Communication in numbers]. Retrieved from http://www.edee.gr/files/Cencus/Final_EDEE_Census\%202011.pdf

L’Etang, J. (2004). Public relations in Britain. Mahwah, NJ: Lawrence Erlbaum Associates.

L'Etang, J. (2008). Writing PR history: issues, methods and politics. Journal of Communication Management, 12 (4), 319-335.

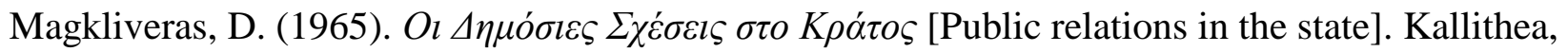

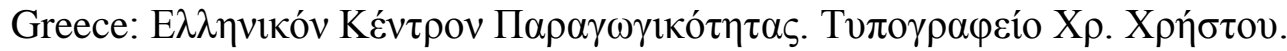

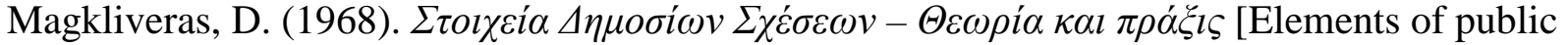

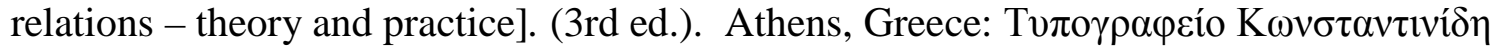

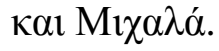

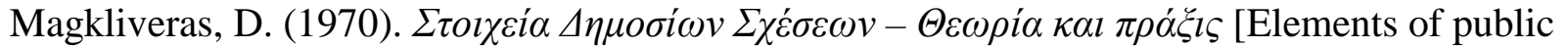

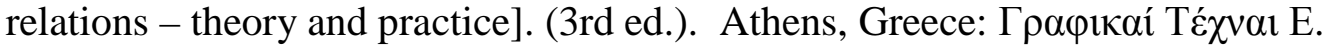

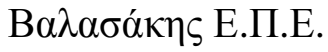

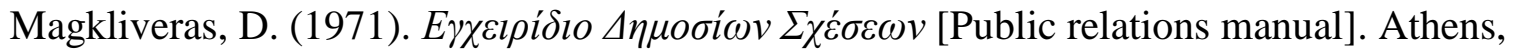

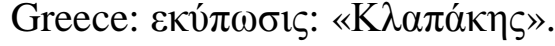




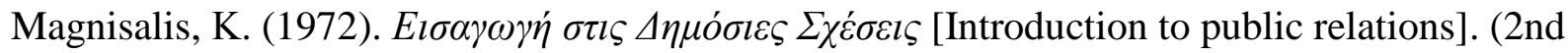

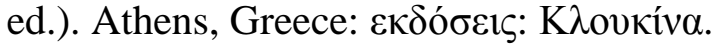

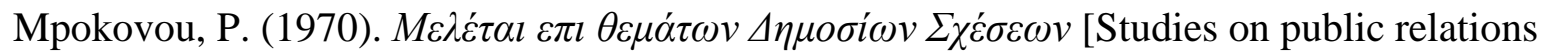
issues]. Thessaloniki, Greece.

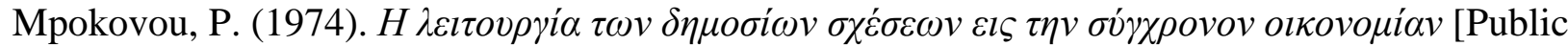
relations function in modern economy]. Thessaloniki, Greece.

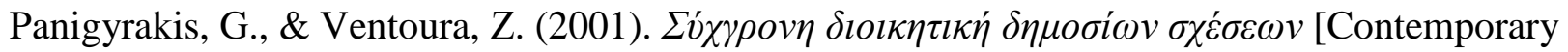

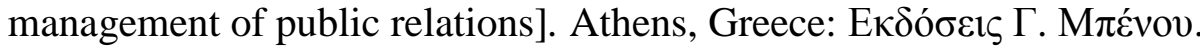

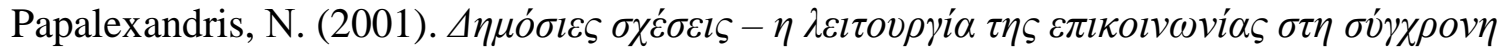
$\varepsilon \pi \imath \chi \varepsilon i \rho \eta \sigma \eta$ [Public relations - the function of communication in modern business].

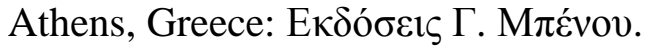

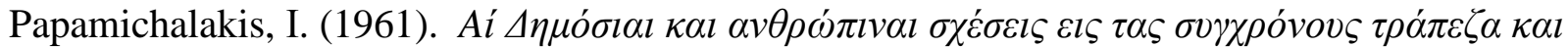

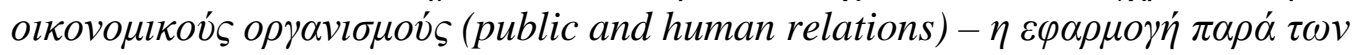

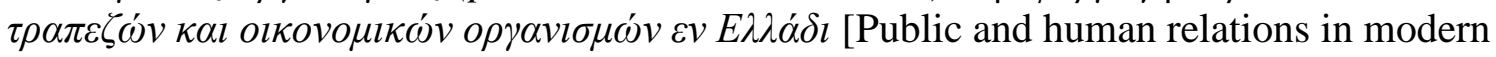
banks and economic organizations (public and human relations - function in banks and

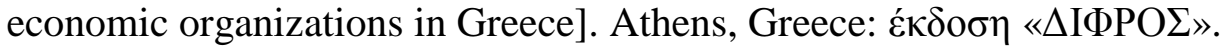

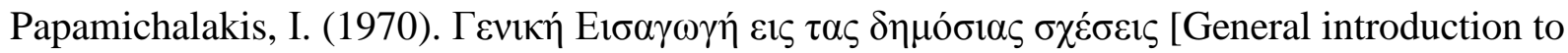
public relations]. Athens, Greece: «K $\Lambda$ AПAKH $\Sigma »$.

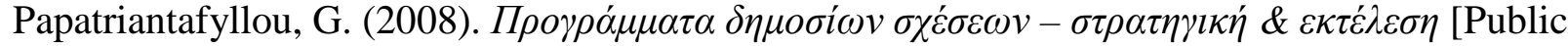

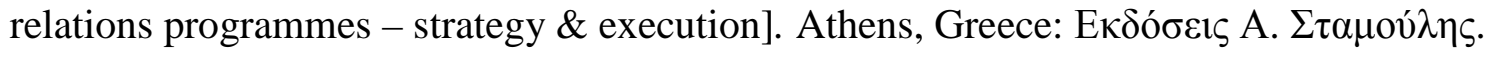

Raaz, O. \& Wehmeier, S. (2011), Histories of public relations: Comparing the historiography of British, German and US public relations. Journal of Communication Management, 15 (3), 256-275.

Rodriguez Salcedo, N. (2008). Public relations before 'public relations' in Spain: an early history (1881-1960). Journal of Communication Management, 12 (4), 279-293.

Taylor, P. (1999). British propaganda in the $20^{\text {th }}$ century - selling democracy. Edinburgh: Edinburgh University Press.

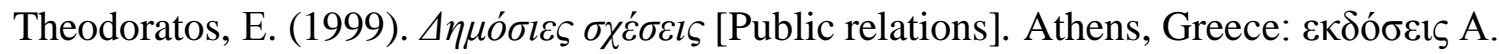

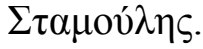

Tosh, J. (2009). The pursuit of history. London: Longman.

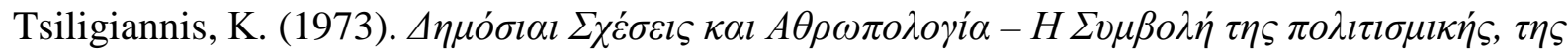

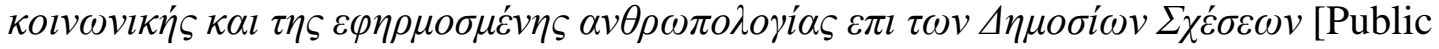


relations and anthropology - the contribution of cultural, social and applied anthropology

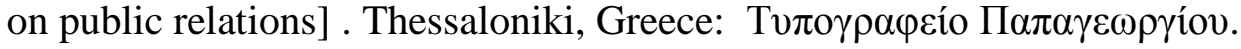

Watson, T. (2008). Creating the cult of a saint: Communication strategies in 10th century England. Public Relations Review, 34(1), 19-24.

Watson, T. (2011). Archive of the International Public Relations Association. Bournemouth: Bournemouth University. Available at: http://blogs.bournemouth.ac.uk/historyofpr/

Watson, T. (2013). International History of Public Relations Conference, keynote speech. Proceedings of the International History of Public Relations, UK. Available at: http://blogs.bournemouth.ac.uk/historyofpr/

Yannas, P. (2004). Greece. In B. van Ruler, \& D. Vercic (Eds.), Public Relations and Communication Management in Europe. A nation-by-nation introduction to public relations theory and practice (pp. 169-185). Berlin: Mouton de Gruyter.

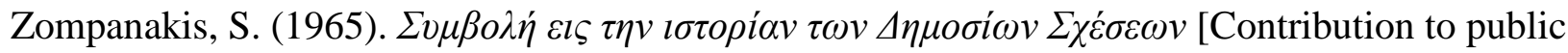

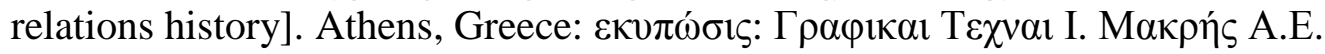

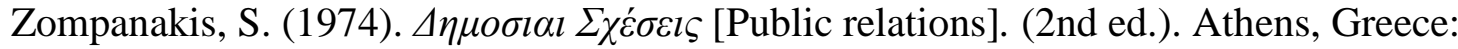
$\varepsilon \kappa v ́ \pi \omega \sigma \iota \varsigma: ~ « К \lambda \alpha \pi \alpha ́ \kappa \eta \varsigma »$.

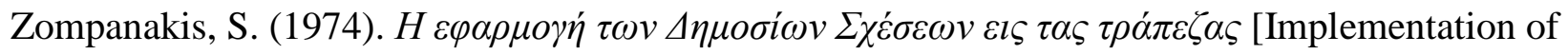
public relations in banks]. Athens, Greece: $\varepsilon \kappa u ́ \pi \omega \sigma \iota \varsigma: ~ « K \lambda \alpha \pi \alpha ́ \kappa \eta \varsigma »$. 